\title{
Experimental Measurement and Computational Investigation on the Effect of Inlet Winglet Turbulators on the Heat Exchange Behaviour of Radiator Tubes
}

\author{
C. Sadhasivam ${ }^{\dagger}$, R. Thirumalai ${ }^{2}$ and T. Kua-anan ${ }^{3}$ \\ ${ }^{1}$ Department of Mechanical Engineering, Saveetha University, Chennai, India \\ ${ }^{2}$ Department of Mechanical Engineering, Dr. N. G. P. Institute of Technology, Coimbatore, India \\ ${ }^{3}$ Environmental Assessment and Technology for Hazardous Waste Management Research Center, Faculty of \\ Environmental Management, Prince of Songkla University, Hadyai, Songkla
}

†Corresponding Author Email: sahaasyan@gmail.com

(Received May 15, 2018; accepted July 18, 2018)

\begin{abstract}
In this present work, a heat exchanger test set up is configured as a closed circle framework comprising of a storage tank (14 litres), a pump, a detour line, heat exchange test area, a water cooler and a flow meter. Numerical investigations is carried out using computational fluid dynamics (CFD) on a device was comprising a basic channel with rectangular cross area utilizing water as the working liquid. The influence of geometry and flow parameters on the pressure drop across the radiator tube test section is investigated. Inlet winglets were utilized as a part of the present numerical study. The goal of the present numerical study is to understand the impact of these inlet winglets set inside the car radiator tubes, on the general heat exchange performance of the radiator. The calculations were carried out on a finite volume based code ANSYS fluent15.0, with one, two and three winglets set toward one side mass of the tube, at three different Reynolds numbers and with three winglet configurations set on every one of the end of the tube, at five distinctive Reynolds numbers. It is observed for the experimental results and CFD values heat the optimum number ribbed winglets for the pressure configurations is two and three gives a temperature rise of $10 \mathrm{c}$ and its pressure drop of $20.10 \mathrm{~Pa}$.
\end{abstract}

Keywords: Winglets; Heat transfer coefficient; Radiator tube; CFD.

\section{INTRODUCTION}

The radiator is a critical role in an automobile. It disperses the waste heat produced after the burning procedure and helpful work has been finished. The viability with which waste heat is removed from the Engine is pivotal in safeguarding the material uprightness of the Engine and improving the execution of the Engine. The utilization of Computational Fluid Dynamics (CFD) displaying recreation of mass flow rate of air going over the containers of a car radiator was completed by Kim and Bullard (2002). A significant part of the work is going ahead to expand the estimation of convective heat exchange coefficient on the comparative patters this work is being coordinated on expanding the estimation of $h$ by altering the rpm of the fan with the assistance of electrical controller/changing the windings of the engine. A few studies were made on impacts of variable mass flow rate of the coolant in the radiator, the rate of flow is controlled by the Kim and Bullard (2002) concentrated tentatively the air-side warm and pressure driven execution of multi-louvered balance aluminium heat exchangers. Phan (2011) examined the channel dampness and mass exchange execution of the tubeline. Concentrates on the utilization of Nano liquids in minimal heat exchangers were completed. A few studies to build the rate of heat exchange were conveyed utilizing wound tape by Zhong (2005).

Numerical investigation of heat exchange and weight drop in a heat exchanger that is outlined with various shape pin balances were completed. A few studies were additionally done for Improving Radiator Efficiency via Air Flow Optimization. Concentrates on the impact of blockage of earth on Engine radiator in the Engine cooling framework were done by S. D. Oduro [10]. Cowell et al (1995) and Achaichia et al (1988) discussed the heat exchange execution of multilouvered balance in CHE. They called attention to that the louvered 
balance CHE gives preferable heat exchange execution over different sorts of heat exchanger because of the louver exhibit's flow coordinating properties which brought about the augmentation in speed of the working liquid in respect to the basic level plate surfaces. The impact of geometrical and ecological parameters on warm and water powered execution of louver blade level plate CHE are tentatively concentrated on by Zhong and Jacobi (2005). Jung and Assanis (2006) discussed and introduced the centre size on the heat dismissal rate. Test examinations will be completed in a basic conduit with rectangular cross area utilizing water as the working liquid. To evaluate the heat exchange upgrade of a radiator tube by the Triangular winglet turbulator(s) set on the base mass of the radiator tube tentatively. Srinivasan (2017) studied and analysed about the missile with grid fins and the effect on flow drag using ANSYS. Godwin (2017) and Lakshmanan (2017) investigated about the optimum parameters for obtaining the best performance using alternate fuels of IC engines working under the current cooling system using Nanofluids.

The improvement will be seen by the expanded liquid side temperature ascend over the tube, with water as the working liquid. To examine the impact of number of winglet turbulators set on the base mass of the radiator tube, three varieties in the triangular winglet turbulators will be concentrated on. The main setup will be considered with standout triangular turbulator; the second setup with two and third setup with three quantities of triangular turbulators put at the base mass of the radiator tube.

\section{EXPERIMENTAL SETUP}

\subsection{Details of the Experimental Procedure}

The schematic representation of the test setup is shown in Figure 2.1. This heat exchange test set up is used as a closed circle configurations comprising of a storage tank (14 liters), a pump, a detour line, a heat exchange test area, a water cooler and a flow meter. The heat exchange test section has a rectangular cross-section $\left(200 \mathrm{~cm}^{2}\right)$ with length and width of $20 \mathrm{~mm}$ and $10 \mathrm{~mm}$ respectively and was produced utilizing copper sheet (1 mm thickness); and the overall length were $1000 \mathrm{~mm}$.

The experimental setup consists of four test sections

(i) Smooth rectangular sectioned radiator tube

(ii) Radiator tube with 1 winglet turbulator

(iii) Radiator tube with 2 winglet turbulators

(iv) Radiator tube with 3 winglet turbulators

Two thermocouples ( $\mathrm{K}$-Type) were embedded into the flow at the inlet and the outlet of the test segment for measuring the mass temperature of the flowing liquid and another six thermocouples of the same type were fixed on the surface of the test area at various locations (thermocouples from the passage side of flow is $0,200,400,600,800$ and $1000 \mathrm{~mm}$ ) to check surface temperature varieties amid tests. To get a consistent heat flux limit condition, the heat test area was heated by radiator which is sustained by a steady air conditioning power with the capacity of $1500 \mathrm{~W}$. Keeping in mind the end goal to minimize heat misfortune to the surroundings, the heat exchange area is separated by a 10 -cmthick fiberglass covers. A water cooler after the test segment is used to keep the temperature consistent at the inlet of the test segment. The key parameters that were measured incorporate electric force inputs, flow rate, temperatures (inlet and outlet) and external wall temperatures along the heat move area in 4 locations. The flow rate through the circle was controlled with detour line.

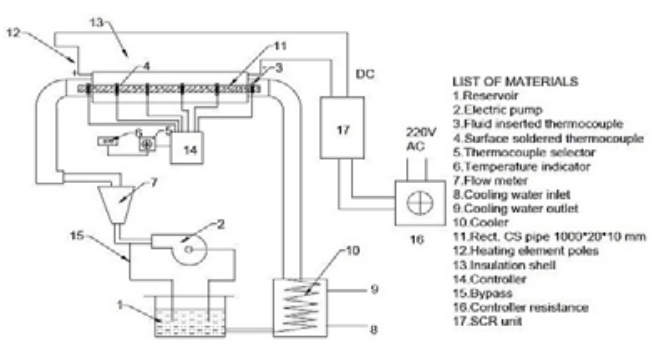

Fig. 1. Schematic diagram of the experimental setup

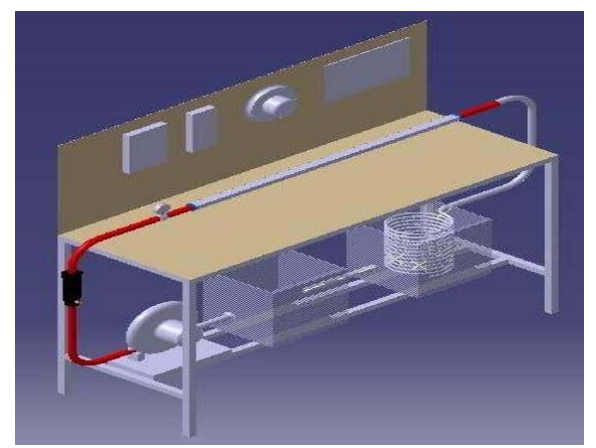

Fig. 2. CAD model of the test facility

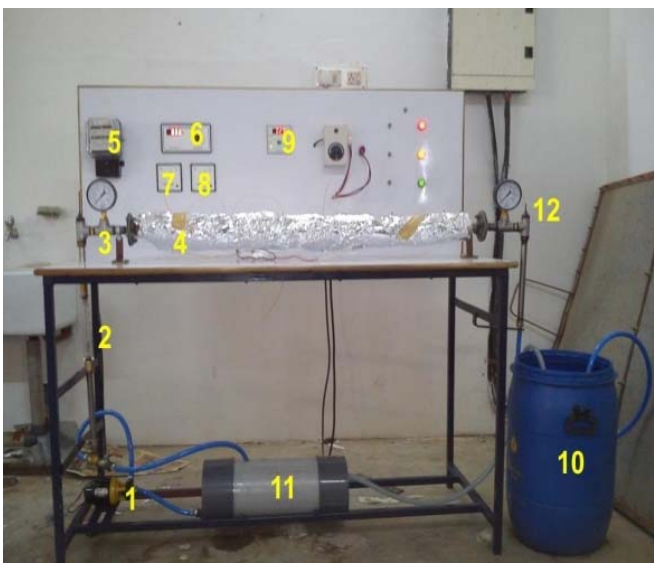

Fig. 3. Photograph of the test facility

1.Pump, 2.Rotameter, 3.Pressure gauge 4.Rectangular duct, 5.Energy meter, 6.Temp. selector

7.Ammeter, 8.Voltmeter, 9.Temp. controller, 10.Heat exchanger, 11.Reservoir, 12.Thermocouple

\section{COMPUTATIONAL TECHNIQUE}

Computational examinations were completed for 
the present configurations and the results discussed here. Appropriate solver setting, turbulence model were recognized from the writing and the limit conditions for the reenactments were taken from the present test. Numerical examinations depended on
3D enduring state conjugate heat exchange investigation to gather flow and heat exchange qualities of the safeguard liquid utilizing the FVM based code Ansys 15.0.

Table 1 Influence of the flow Reynolds number and number of winglets on the heat transfer enhancement

\begin{tabular}{|c|c|c|c|c|c|c|c|c|c|}
\hline \multirow{2}{*}{$\begin{array}{c}\text { Flow } \\
\text { rate }\end{array}$} & $\begin{array}{c}\text { Reynolds } \\
\text { No }\end{array}$ & \multicolumn{2}{|c|}{\begin{tabular}{c} 
Smooth Duct \\
\cline { 3 - 10 }
\end{tabular}} & $\begin{array}{c}\text { One winglet- Bottom } \\
\text { wall }\end{array}$ & \multicolumn{2}{|c|}{$\begin{array}{r}\text { Two Winglets - Bottom } \\
\text { wall }\end{array}$} & \multicolumn{2}{|c|}{$\begin{array}{c}\text { Three Winglets - } \\
\text { Bottom wall }\end{array}$} \\
\hline $\mathrm{kg} / \mathrm{s}$ & $\sim$ & $\mathrm{Pa}$ & ${ }^{\circ} \mathrm{C}$ & $\mathrm{Pa}$ & ${ }^{\circ} \mathrm{C}$ & $\mathrm{Pa}$ & ${ }^{\circ} \mathrm{C}$ & $\mathrm{Pa}$ & ${ }^{\circ} \mathrm{C}$ \\
\hline 0.1 & 6000 & 2.00 & 3.00 & 2.50 & 3.50 & 3.20 & 3.80 & 5.20 & 4.00 \\
\hline 0.2 & 12000 & 5.00 & 4.50 & 5.70 & 5.20 & 6.20 & 5.54 & 8.00 & 5.60 \\
\hline 0.3 & 18000 & 8.00 & 6.00 & 8.80 & 7.00 & 9.50 & 7.60 & 12.50 & 8.00 \\
\hline 0.4 & 24000 & 12.00 & 8.00 & 13.20 & 9.00 & 15.00 & 9.20 & 17.00 & 9.20 \\
\hline 0.5 & 30000 & 16.00 & 9.00 & 17.50 & 10.50 & 18.50 & 10.00 & 20.10 & 10.00 \\
\hline
\end{tabular}

\subsection{Radiator of the Physical Model}

The physical model of the car radiator tube considered for the present study comprised of four test segments.

(i) Smooth rectangular segmented radiator tube

(ii) Radiator tube with 1 winglet turbulator

(iii) Radiator tube with 2 winglet turbulators

(iv) Radiator tube with 3 winglet turbulators

The schematic portrayals of the physical test areas utilized are appeared as a part of Fig.3. Vortices delivered behind the winglet tabulators will help in upgrading the turbulence blending of the cool and the hot liquids flows. This is normal incompressible heat and mass exchange reenactments utilizing the RANS (Reynolds Arrived at the midpoint of Navier Stirs) approach with Realizable k-conditions as the turbulence conclusion will be done. The outcomes from the calculations will be approved with the accessible trial comes about and further results from the numerical forecasts will be exhibited. The limit conditions utilized for the present CFD reenactments are appeared in the boundary conditions used can be listed as shown in Figure-8.

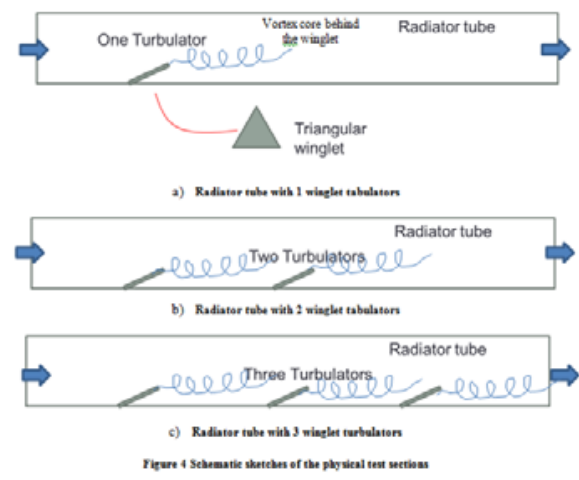

Fig.4. Schematic sketches of the physical test sections

\section{RESULTS AND EXAMINATIONS}

The outcomes from the calculations led on the radiator tube with winglets is outlined and discussed in this section. Validation of the present computational technique was done with writing and the present results are examined in the later areas of this section.

\subsection{Validation of the Computational Approach}

To concentrate logically the heat exchange and weight drop qualities of a coolant liquid going through smoothed container of an Indian vehicle radiator, with and without rib turbulators, as appeared in Figure 5. From the physical model identified, the computational domain as shown in Figure 5 was modeled. The meshed model is shown in Figure 6.

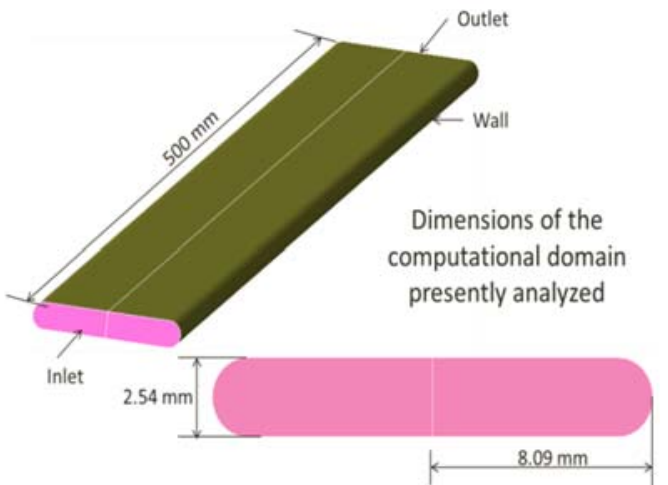

Fig. 5. Computational domain details used for validation study

The solver settings used for the validation study is shown below:

- Inlet boundary condition

- Specified velocity @ inlet=25.53185 mm/s @363 K 
- Equivalent to a $\operatorname{Re}=100$

- Outlet boundary condition

- Open to atmosphere (assumption) @ $303 \mathrm{~K}$

- Sufficient to estimate the system pressure drop - in this case, the flattened tube

- Wall boundary condition

- Lose heat to ambient by convection

- Specified heat loss coefficient: $50 \mathrm{~W} / \mathrm{m} 2-\mathrm{K}$

- Free flow temperature: $303 \mathrm{~K}$

- Flow model

- Laminar

- Heat transfer modes considered

- Convection only (Conduction within the wall thickness and radiation heat loss not considered)

- Working fluid

- Base fluid: 60:40 Ethylene Glycol: Water
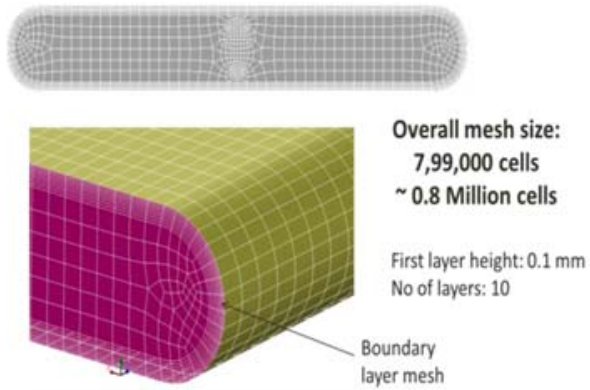

Fig. 6. Meshed computational domain

The computations were carried out and the comparison of the results with that of the corresponding experimental work reported in the literature is presented in Figure 7.

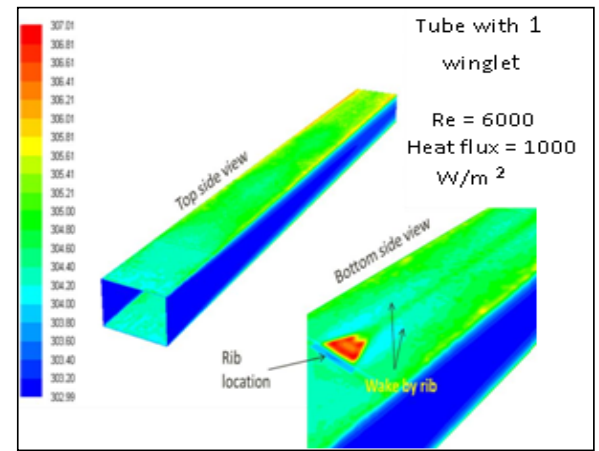

Fig. 7. Comparison of present CFD results with experiments

4.2 Impact of Number of Winglets and Reynolds Number

The impact of the quantity of winglets set on the base mass of the radiator tube is discussed in this section. The shape of divider temperature on the smooth radiator tube is shown in Fig., for a water flow rate of $0.1 \mathrm{~kg} / \mathrm{s}$. Since the top and base Wall are heated with a consistent heat flux value of
$1000 \mathrm{~W} / \mathrm{m} 2$, these surfaces are indicating higher temperature than the side surfaces. Most noteworthy temperatures are seen toward the edges of the pipe nearer to the way out of the channel, as this zone is not reached by the standard liquid because of the relation of the moderate boundary layer in this zone. The contours of the temperature on the radiator tubes with one winglet are shown in Fig.8.There was a higher temperature zone behind the winglet. To support down flow, a blue zone can be discovered which is because of the communication of the vortices delivered by the winglet. This flow phenomenon can be clarified better with the flow lines discharged from the channel of the radiator tube with single winglet, as appeared in Fig.8.

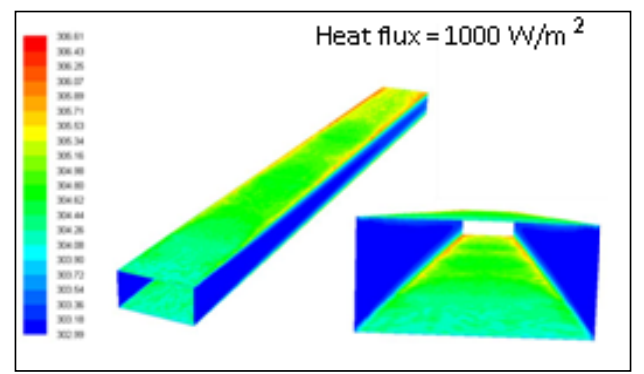

Fig. 8. Contours of temperature on the radiator tube with 1 winglet.

The comparison showed good agreement and hence the present computations were carried out using the same methodology.

The contours of wall temperature on the radiator tube with two winglets and three winglets are shown in Figs. and respectively. The wake zone and the increased turbulence can be observed from the contours. An increased turbulence will eventually result in the increased fluid outlet temperature. The wake zone and the expanded turbulence can be seen from the shapes. An increased turbulence will inevitably bring about the increased liquid outlet temperature. Table 1 Compares the fluid pressure drop and temperature rise with number of winglets Flow rate $0.1 \mathrm{~kg} / \mathrm{s}$ (Reynolds number $=6000$ )

The relative increment in the Pressure drop and the comparing temperature ascend in the smooth radiator tube are shown in Fig.9, with differing flow Reynolds number.

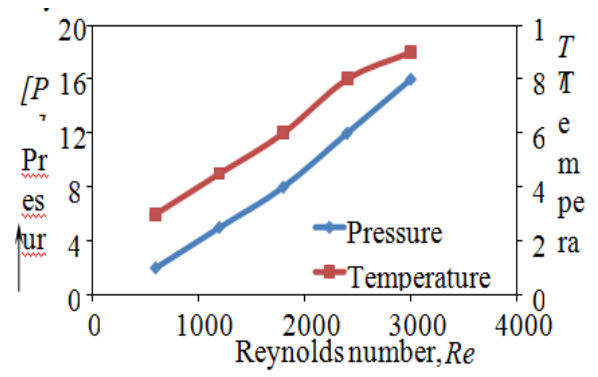

Fig. 9. Relative increase in the pressure drop and the corresponding temperature rise - Smooth channel- radiator tube with 1 winglet

\section{CONCLUSION}

The following are the conclusions drawn from the 
experimental work on the heat transfer enhancement in the automotive radiator tube with triangular winglets and the pressure drop and temperature increase wit increase in Reynolds number. The temperature and pressure drop increase with increase in the number of winglets. It is observed that there was a higher temperature zone behind the winglet. Assist down flow, a blue zone can be discovered which is because of the communication of the vortices delivered by the winglet. This flow characteristic can be clarified better with the flow lines discharged from the channel of the radiator tube with single winglet. CFD simulations were carried out for the ducts with triangular winglet tabulators Ducts with winglets were found to have higher temperature raise associated with higher pressure drop. The optimal number of winglets was found to be "two" Computational results were in good agreement with that of experiments.

\section{REFERENCES}

Achaichia, A. and T. A. Cowell (1988) Heat exchange and weight drop qualities of level tube and louvered plate blade surfaces, Exploratory Warm and Liquid Science 1(2), 147-157.

Cowell, T. A., M. R. Heikal, and A. Achaichia (1995) Flow and heat move in conservative louvered balance surfaces, Test Warm and Liquid Science 10(2), 192-199.

Godwin Antony, A., S. Dinesh, K. Rajaguru, V. Vijayan (2017) Analysis and Optimization of Performance Parameters in Computerized I.C. Engine Using Diesel Blended with Linseed Oil and Leishmaan's Solution, Mechanics and
Mechanical Engineering 21(2), 193-205.

Jung, D. and D. N. Assanis (2006) Numerical demonstrating of cross flow smaller heat exchanger with louvered blades utilizing warm resistance idea, SAE Paper 2006-01-0726.

Kim, M. H. and C. W. Bullard (2002) Air-side warm water driven execution of multi-louvered blade aluminium heat exchangers, International Diary of Refrigeration 25(3), 390-400.

Lakshmanan, P., P. Kaliyappan, M. Ranjithkumar, K. Aravinth, D. Vakkachan, C. Moorthy and S. Kumar (2017) An Experimental Investigation to Study the Performance and Emission Characteristics of Chicken Fat Oil Fuelled DI Diesel Engine, Journal of Applied Fluid Mechanics, 10, Special Issue, 85-91.

Phan, T. L., K. S. Chang, Y. C. Kwon, and J. T. Kwon, (2011) Trial study on heat and mass exchange qualities of louvered blade tube heat exchangers under wet condition, Worldwide Correspondences in Heat and Mass Exchange 38(7), 893-899.

Srinivasan, R., V. Vijayan and K. Sridhar (2017) Computational Fluid Dynamic Analysis of Missile with Grid Fins, Journal of Applied Fluid Mechanics,10, Special Issue, 33-39.

Zhong, Y. and A. M. Jacobi (2005) A test investigation of louver fin level tube heat exchanger execution under icing conditions, in Proceedings of the fifth Worldwide Conference on Upgraded, Smaller and Ultra Minimal Heat Exchangers: Science, Building and Innovation, Designing Gatherings Global, Hoboken, NJ, USA. 